\title{
Fodmap's Restricted Diet in Patients with Irritable Gut Syndrome: A Systematic Review
}

\author{
Sander BQ*, Coelho AT, Oliveira REM, Avance AD, Melado CF, Marques JM, Veríssimo AE, Coelho CT, Bertges \\ LC, Hoerlle FR, Dantas LC, Barbosa ERA, Richene CO, Moura TA, Canejo GC, Portela ES, Castro CHR, Vieira \\ JP, Rodrigues LT, Ribeiro DH, Oliveira FEM, Barbosa RC, Rezende FA, Barcellos HB, Brito RO, Mendonça \\ FPRR, Silva JA and Eller NA
}

Sander Medical Center, Brazil

*Corresponding author: BQ Sander, Sander Medical Center, Brazil.

Received Date: March 01, 2021

Published Date: March 15, 2021

\section{Introduction}

Introduction: Irritable bowel syndrome (IBS) is an inflammatory bowel disease that has a high prevalence among the world population. Dietary interventions are considered an important intervention for the treatment and control of IBS. The diet restricted in FODMAPs, a group of fermentable carbohydrates, has been studied, since it is able to reduce symptoms such as abdominal pain, bloating and diarrhea.

Objective: To verify the role of the FODMAP's restrictive diet in the treatment and control of irritable bowel syndrome.

Methods: The most relevant studies originally published in English, Portuguese and Spanish were analyzed using the MEDLINE (National Library of Medicine and National Institutes of Health) and SciELO databases as reference. In order to select the studies with the greatest scientific evidence, we only contemplate clinical trials and review studies. The search strategy used the following keywords: "irritable bowel syndrome" and "FODMAP's restricted diet". To identify the designs of the studies, the following terms were used: clinical trials.

Results: Initially, 117 studies were identified involving irritable bowel syndrome and the Foodmap diet. However, after applying the Clinical Trials filters, 10 studies were found. After reading the articles found and excluding them from the abstracts, 5 articles were selected involving the theme for analysis and inclusion in the scope of this review.

Conclusion: The restricted diet in FODMAPs proved to be very effective in improving general and specific symptoms of irritable bowel syndrome, especially abdominal pain, bloating and diarrhea.

Keywords: Irritable bowel syndrome; Restricted Diet in FODMAP

\section{Introduction}

Irritable bowel syndrome (IBS) is an inflammatory bowel disease that has a high prevalence among the world population. The disease is believed to affect $7-15 \%$ of the world population, mainly women, under 50 years old. Symptoms are characterized by recurrent episodes of functional gastrointestinal symptoms whose pathophysiological mechanisms are not completely clear, including abdominal pain, bloating, constipation and / or diarrhea [1]. Although one has a pathophysiology not yet clarified, it is known that the diet has an important role in IBS. Hypersensitivity to certain foods can play a role in causing low-grade intestinal inflammation, increased permeability of the epithelial barrier and visceral hypersensitivity. Bioactive chemicals in food, for example salicylates, can also contribute and trigger gastrointestinal symptoms in IBS, possibly inducing visceral hypersensitivity after chronic exposure [2]. The restriction of a group of fermentable carbohydrates, called FODMAPs (fermentable oligosaccharides, 
disaccharides, monosaccharides and polyols), which include fructooligosaccharides (FOS), galacto-oligosaccharides (GOS), disaccharides (for example, lactose), monosaccharides (for example, fructose ) and polyols (eg, sorbitol), came into question for the treatment of IBS [3].

Their logic is that there are several individuals who barely absorb or are sensitive to FODMAPs and, if these foods are eaten, they can result in symptoms such as bloating, diarrhea, gas, constipation or abdominal pain that are often interpreted as IBS. FODMAPs, when poorly absorbed, are highly osmotic substances that can cause an influx of water in the colon and result in diarrhea, or by fermentation by colon bacteria can lead to excessive gas production [4]. The aim of this study is to verify the role of the FODMAP's restrictive diet in the treatment and control of irritable

\section{Results}

Table 1: Summary of studies and their main results involving the restrictive foodmap diet in irritable bowel syndrome.

\begin{tabular}{|c|c|c|c|c|}
\hline Study & Design & Intervention & Treatment Time & Outcome \\
\hline $\begin{array}{l}\text { Staudacher, et } \\
\text { al. [9] }\end{array}$ & $\begin{array}{l}\text { Randomized con- } \\
\text { trolled study }\end{array}$ & $\begin{array}{l}\text { Diet with low } \\
\text { foodmap index }\end{array}$ & 4 weeks & $\begin{array}{l}\text { In a placebo-controlled study of IBS patients, a low FODMAP diet is } \\
\text { associated with adequate symptom relief and significantly reduces } \\
\text { symptom scores compared to placebo. It is not clear whether the } \\
\text { changes resulted from the collective restriction of FODMAP or the } \\
\text { removal of a single component, such as lactose. }\end{array}$ \\
\hline Cox, et al. [10] & $\begin{array}{l}\text { Randomized, } \\
\text { double-blind, } \\
\text { placebo-con- } \\
\text { trolled, cross-over, } \\
\text { re-challenge } \\
\text { study. }\end{array}$ & $\begin{array}{l}\text { Restricted diet in } \\
\text { foodmaps }\end{array}$ & 3 days & $\begin{array}{l}\text { At the relatively high doses used, fructans, but not GOS or sorbitol, } \\
\text { exacerbated functional gastrointestinal symptoms (SGF) in inactive } \\
\text { IBD. Further research is needed to determine whether a low FOD- } \\
\text { MAP diet reduces SGF in IBD and the degree of FODMAP restriction } \\
\text { needed to improve symptoms. }\end{array}$ \\
\hline $\begin{array}{l}\text { Valeur, et al. } \\
\text { [11] }\end{array}$ & $\begin{array}{l}\text { Randomized con- } \\
\text { trolled study }\end{array}$ & $\begin{array}{l}\text { Restricted diet on } \\
\text { foodmap }\end{array}$ & 24 hours & $\begin{array}{l}\text { Dietary restriction to FODMAP markedly modulated fecal fermen- } \\
\text { tation in patients with IBS. Saccharolytic fermentation decreased, } \\
\text { while proteolytic fermentation increased, apparently independent } \\
\text { of symptoms. }\end{array}$ \\
\hline Berg, et al. [3] & $\begin{array}{l}\text { Randomized con- } \\
\text { trolled study }\end{array}$ & $\begin{array}{l}\text { Fructose restric- } \\
\text { tion }\end{array}$ & 12 weeks & $\begin{array}{l}\text { Fructose restriction improves symptoms in a subset of patients with } \\
\text { IBS. A diet test followed by a provocation test assessed by subjec- } \\
\text { tive global assessment can identify most responders to fructose } \\
\text { restriction. }\end{array}$ \\
\hline $\begin{array}{l}\text { Erickson, et } \\
\text { al. [1] }\end{array}$ & $\begin{array}{l}\text { Randomized } \\
\text { controlled, dou- } \\
\text { ble-blind study }\end{array}$ & $\begin{array}{l}\text { Nutritional sup- } \\
\text { plements with low } \\
\text { foodmap index }\end{array}$ & 4 weeks & $\begin{array}{l}\text { All treatments were well tolerated in healthy participants. The low } \\
\text { formulas of FODMAP resulted in less response to the hydrogen of } \\
\text { respiration compared to the positive control and may be better } \\
\text { tolerated in individuals with IBS. Further research should be con- } \\
\text { ducted to better understand the GI tolerance of low FODMAP ONS in } \\
\text { individuals with IBS. }\end{array}$ \\
\hline
\end{tabular}

Initially, 117 studies were identified involving irritable bowel syndrome and the Foodmap diet. However, after applying the Clinical Trials filters, 10 studies were found. After reading the articles found and excluding them from the abstracts, 5 articles were selected involving the theme for analysis and inclusion in the scope of this review. In (Table 1) we will present a summary of the works selected and reviewed in the present study.

\section{Discussion}

Irritable bowel syndrome (IBS) is a chronic inflammatory bowel disease that has a high prevalence and incidence. IBS affects bowel syndrome.

\section{Method}

\section{Research Strategies}

The most relevant studies originally published in English, Portuguese and Spanish were analyzed using the MEDLINE database (National Library of Medicine and National Institutes of Health). In order to select the studies with the greatest scientific evidence, we only contemplate clinical trials and review studies. The search strategy used the following keywords: "irritable bowel syndrome" and "FODMAP's restricted diet". To identify the designs of the studies, the following terms were used: clinical trials. The inclusion and exclusion criteria were applied based on the types of studies, language and type of therapy from the points raised in each exposed item. 
patients have focused on fiber, caffeine, alcohol and fat restriction, but in recent years, the low FODMAP diet has been considered a newcomer to IBS dietary management and a considerable amount evidence on the mechanisms and clinical efficacy of this new diet [5].

FODMAPs are a group of compounds that includes oligosaccharides, disaccharides, monosaccharides and polyols. The definition of the components is based on functional characteristics such as being poorly absorbable and highly fermentable in the intestine. These compounds can exacerbate IBS symptoms by increasing the volume of water in the small intestine, producing colonic gas and intestinal motility [6]. However, FODMAPs have an important physiological effect, since they increase the volume of feces, improve calcium absorption and modulate immune function, in addition to decreasing serum cholesterol levels, triacylglycerols and phospholipids. Along with this, these compounds help the growth of some microbial groups, such as bifidobacteria [7]. Studies have shown that a diet with a low intake of FODMAPs significantly reduced the symptoms of irritable bowel syndrome, including abdominal bloating. This is because ingestion of FODMAP increases the delivery of readily fermented substrates and water to the distal small intestine and proximal colon, causing luminal distention and functional bowel symptoms. The hypothesis of the FODMAP concept is that a global constraint should be more effective than a constraint, in controlling IBS symptoms [8].

Another study carried out in 2014, involving 162 patients, concluded that the restricted diet in FODMAPs leads to adequate relief of gastrointestinal symptoms in $57 \%$ of patients, compared with $38 \%$ of patients who receive false dietary advice. Although this finding has not reached statistical significance, all of the reported clinical results point to the clinical efficacy of the restricted diet in FODMAP, compared to placebo, making it directly relevant to clinical practice [9]. Several clinical trials, therefore, have reported that reducing foods with a high FODMAP index achieves adequate symptom relief in approximately $70 \%$ of patients with IBS [10]. In a recent meta-analysis, Marsh, et al. [11] reported the effectiveness of a low diet in FODMAP on gastrointestinal functional symptoms associated with irritable bowel syndrome, and found a significant improvement in symptom severity and quality of life scores compared to patients who received a normal Western diet. Significant reductions in abdominal pain and bloating have also been reported in patients who received a low FODMAP compared to those who received a medium or high FODMAP diet. Therefore, there is evidence that a diet restricted in FODMAP can have a favorable impact on IBS symptoms, especially abdominal pain, bloating and diarrhea. However, it remains to be demonstrated whether a diet with a low FODMAP index is superior to conventional diets for IBS, especially in the long term [10].

\section{Conclusion}

Irritable bowel syndrome is an inflammatory bowel disease with high prevalence among the population. The dietary restriction of some food groups is shown as an alternative to reduce the symptoms caused by the syndrome. In this systematic review 05 articles were analyzed, evaluating the effectiveness of the restricted diet in FODMAPs in controlling and treating IBS. It was concluded, then, that diet restricted in FODMAPs proved to be quite effective in improving general and specific symptoms of irritable bowel syndrome, mainly abdominal pain, bloating and diarrhea.

\section{Acknowledgement}

None.

\section{Conflict of Interest}

No conflict of interest.

\section{References}

1. Altobelli E, Del Negro V, Angeletti PM, Latella G (2017) Low-FODMAP Diet Improves Irritable Bowel Syndrome Symptoms: A Meta-Analysis. Nutrients 9(9): 940

2. Cozma-Petrut A, Loghin F, Miere D, Dumitrascu DL (2017) Diet in irritable bowel syndrome: What to recommend, not what to forbid to patients. World J Gastroenterol 23(21): 3771-3783.

3. Rao SS, Yu S, Fedewa A (2015) Systematic review: dietary fibre and FODMAP-restricted diet in the management of constipation and irritable bowel syndrome. Aliment Pharmacol Ther 41(12): 1256-1270.

4. Cuomo R, Andreozzi P, Zito FP, Passananti V, De Carlo G, et al. (2014) Irritable bowel syndrome and food interaction. World J Gastroenterol 20(27): 8837-8845.

5. Turco R, Salvatore S, Miele E, Romano C, Maseglia GL, et al. (2018) Does a low FODMAPs diet reduce symptoms of functional abdominal pain disorders? A systematic review in adult and paediatric population, on behalf of Italian Society of Pediatrics. Ital J Pediatr 44(1): 53.

6. Catassi G, Lionetti E, Gatti S, Catassi C (2017) The Low FODMAP Diet: Many Question Marks for a Catchy Acronym. Nutrients 9(3): 292.

7. Dionne J, Ford AC, Yuan Y, Chey WD, Lacy BE, et al. (2018) A Systematic Review and Meta-Analysis Evaluating the Efficacy of a Gluten-Free Diet and a Low FODMAPs Diet in Treating Symptoms of Irritable Bowel Syndrome. Am J Gastroenterol 113(9): 1290-1300.

8. Wong WM (2016) Restriction of FODMAP in the management of bloating in irritable bowel syndrome. Singapore Med J 57 (9): 476-484.

9. Staudacher HM, Lomer MCE, Farquharson FM, Lois P, Fava F, et al. (2017) A Diet Low in FODMAPs Reduces Symptoms in Patients With Irritable Bowel Syndrome and A Probiotic Restores Bifidobacterium Species: A Randomized Controlled Trial. Gastroenterology 153(4): 936-947.

10. Cox SR, Prince AC, Myers CE, Irving PM, Lindsay JO, et al. (2017) Fermentable Carbohydrates [FODMAPs] Exacerbate Functional Gastrointestinal Symptoms in Patients With Inflammatory Bowel Disease: A Randomised, Double-blind, Placebo-controlled, Cross-over, Re-challenge Trial. J Crohns Colitis 11(12): 1420-1429.

11. Marsh A, Eslick EM, Eslick GD (2016) Does a diet low in FODMAPs reduce symptoms associated with functional gastrointestinal disorders? A comprehensive systematic review and meta-analysis. EUR J Nutr 55: 897-906. 